\title{
Thematic Patterns on the Novel Coronavirus Epidemic in Canadian News
}

\author{
Madelyn J. Richards \\ Department of Sociology, MacEwan University
}

\begin{abstract}
A content analysis of Canadian news articles was conducted to examine thematic patterns of coronavirus (COVID-19). Fifty articles were selected on Facebook from five Canadian national news channels, CBC News, CTV, Global News, Huffington Post, and The Globe and Mail. These were selected based on two keywords: coronavirus and COVID-19. Eight thematic categories were established based on keywords. The eight categories were: (1) support, (2) control, (3) health, (4) economy, (5) other countries, (6) government, (7) explanation, (8) industry. The most prevalent themes were government (23\%) and health (23\%). These results indicate Canadian News presents COVID-19 as a serious health-risk and discusses how the Canadian government is responding to the epidemic.
\end{abstract}

\section{Introduction}

A crucial component in emergency response is effective public communication (Wray et al., 2008). Information through news channels can help people take appropriate measures to protect themselves from a threat, preventing illness or injury (Wray et al., 2008). Most often, news media reports risk communication to the public. The World Health Organization Outbreak Communication Guidelines encourages public authorities to engage with the media as soon as a public health threat emerges (Duncan, 2009). Public health threats may be natural disasters, chemical toxins, and infectious diseases (World Health Organization, n.d.). The most recent public health risk is the outbreak of the novel coronavirus disease (COVID-19), originating in China and quickly spreading globally. COVID-19 is a highly contagious virus affecting hundreds of thousands of people worldwide (Lai et al. 2020). On January 15, 2020, the first case of COVID-19 was declared ("Epidemiological summary," n.d.). As there is an increase in outbreaks across Canada, many provinces have declared a state of emergency (Gollom, 2020). Consequently, the epidemic is receiving significant Canadian news coverage.

The media has an immense influence on how Canadians perceive the novel virus, as it is a useful source of health-related information (Schwitzer, 2004). The media can affect the public's behaviour and beliefs about risks. Framing effects theory and social representations theory are two theories describing how the media has an influential effect on the public (Boyd et al., 2009). Framing refers to how the media presents an issue in particular ways that influences how the issue is understood by the public (Scheufele \& Tewksbury, 2007). Through framing, some information about COVID-19 may be highlighted, increasing the salience of the topic, while other information is neglected (Coleman \& McCombs, 2007). Social representations theory links news media to the public through representations of phenomena (i.e. COVID-19) that provides the coherence of beliefs and practices between individuals (Höijer, 2011). Such theories illustrate how the news affects the public's behaviours and beliefs toward a health risk (Boyd et al., 2009).

Lemyre et al. (2009) conducted a national public survey on the public's perception of bovine spongiform encephalopathy (BSE). Using a questionnaire modelled similarly to the National Survey of Health Risk Perception and Acceptability in Canadians survey, the researchers found BSE represented no or little risk to their health; rather, it was a more important issue for social, political, and economic concerns (Lemyre et al., 2009). Similarly, Lemyre et al. (2007) focus group 
study presented similar findings with individuals perceived risk of becoming infected by BSE (as cited in Lemyre et al., 2009). The participants felt they needed to be better informed by the news media regarding BSE and the health risks associated with BSE. This feedback is important to examine how news media is representing information regarding diseases, such as BSE and COVID-19 that rely heavily on decisions and actions taken by the public (Lemyre et al., 2009).

Hilton and Hunt (2011) looked at newspaper stories representation of the swine flu outbreak in the UK. They examined 2,374 newsprint articles published in eight national newspapers with an inclusion criterion defined as swine flu being the primary topic of the article. Over a 12-month period, the researchers identified 44 thematic categories, examined quantitative trends in quarterly periods, and rated the tone of each article (alarmist, reassuring, or neither). The findings indicate the majority of articles that were published in the $2^{\text {nd }}$ third of the year (May-August) were neither alarmist nor reassuring. This suggests news media reporting was highest when there was the first peak in cases, focusing content on the number of cases and deaths and fewer articles being reassuring.

A similar content analysis was done by Boyd et al. (2009) examining Canadian media representations of BSE. They examined articles (309) from the first 10 days after the first confirmed Canadian cases of BSE from four newspapers: The Globe and Mail, The National Post, The Edmonton Journal, and Lethbridge Herald. Quantitative data was collected using 9 categories: (a) health, (b) government, (c) blame, (d) mistrust, (e) definitions, (f) descriptions, (g) control actions, (h) economy, and (i) other. The articles affective attributes were also rated as either positive, neutral, or negative. The results indicate economy was the most prevalent theme with the majority of the articles being negative.

Such reports describe the themes and frames around diseases that are prevalent in news media stories. These recurring themes are important in formulating risk perception in the public and exerts an influence on how diseases are understood by the readers. Thus, a news media content analysis is beneficial to illuminate how risks associated with a disease are received by the general public (Boyd et al., 2009). In the context of the current COVID-19 pandemic, the present study conducted a content analysis on 50 articles published across five Canadian nationwide news channels to examine qualitative and quantitative themes displayed in the articles. This study aims to identify thematic patterns and its prevalence rate.

\section{Method}

Sample and Sample Selection

The sample consisted of 10 articles each from five Canadian national news channels, CBC News, CTV, Global News, Huffington Post (HP) and The Globe and Mail (TGM). These news outlets were chosen due to being accessible nationwide, as well as being the most popular ones, therefore having more viewers (Feedspot, 2020). The articles were collected on the news channels Facebook profile page by selecting articles with keywords (coronavirus or COVID-19). The ten most recent articles were collected. The selection of articles was collected on March 31, 2020. Previous research on swine flu indicates news reports were the highest at the first peak of confirmed cases 3 months after the first confirmed case (Hilton and Hunt, 2011). Canada may be similar, thus making this sampling time preferable. The criteria for including articles consisted of having COVID-19 as the main focus of the article.

\section{Inclusion and Exclusion Criteria}

All articles were included if the story reflected the COVID-19 outbreak, compared COVID-19 to another event, spoke about COVID-19 in another country, and if the story was about government's plans or policy changes due to COVID-19. Again, COVID-19 had to be the main focus of the news story. Any story that mentioned COVID-19 as a secondary topic was not included. The unit of analysis was the words and phrases used in the article's title and body.

\section{Coding Procedure}

Each article was examined independently for keywords that captured the theme of the article. The development of some initial codes was based on a priori categories of previous studies examining media representations of diseases and was adjusted as needed (Boyd et al., 2009; Hilton and Hunt 2011). The patterns in the data can be categorized by (1) support (i.e. describing how people, other countries, and government are providing support), (2) control (i.e. how the disease will be controlled or 
how it is under control), (3) health (i.e. describing aspects of human mental/physical health or safety concerns), (4) economy (i.e. economic wellbeing), (5) other countries (i.e. describing COVID-19

consequences or events in other countries), (6)

government (i.e. policy change, actions), (7) explanation (i.e. explaining an account of something), and (8) industry (i.e. how COVID-19 was impacting industries). A category was chosen that depicted the theme and best described the article. There could be multiple codes for each article (i.e. explanation and control), and categories were only counted once even if there were multiple references to the category.

\section{Results}

Figure 1 shows the themes of articles after two and a half months of the first case in Canada. The majority of themes focused on government (23\%) and health (23\%). Those articles mainly focused on government policy change such as changing court, prison, and school systems or government actions such as cancelling events. Health articles primarily described the growing number of confirmed cases/deaths, and mental health concerns due to COVID-19. The second most prevalent theme was control (20\%). An example may be ordering more ventilators and masks to cope with the increasing COVID-19 cases. Explanation was the third most prevalent theme (15\%) with articles explaining locations of confirmed COVID-19 cases or why there is a rapid increase in some locations. Health and explanation were the greatest overlapping themes. Other countries were not discussed to a great extent (10\%). Support (7.5\%) and economy (7.5\%) were one of the ones least discussed. An example of a support article would be the public paying tribute to health-care workers through various forms. Economy articles primarily discussed the economic fallout from COVID19. Industries (5\%) were the least discussed reviewing how industries (e.g. amazon $\&$ grain industries) are affected by COVID-19.

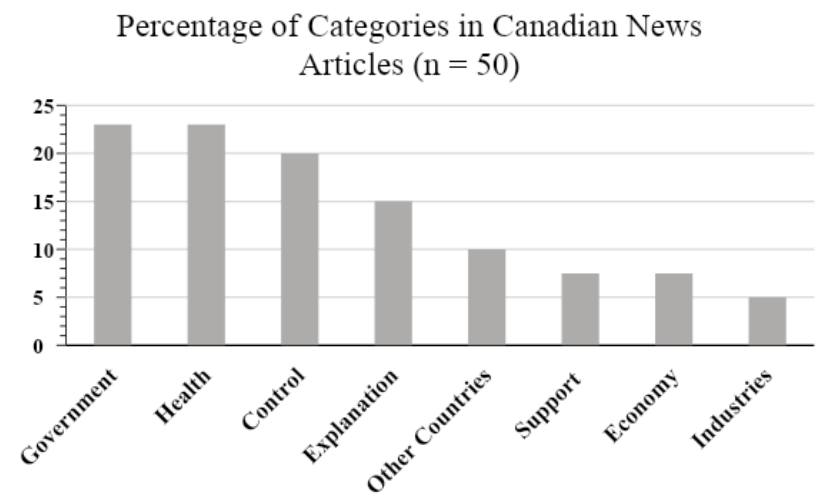

Categories

Fig. 1. Themes of all articles

\section{Discussion}

Results show that themes of government and health were the primary focus on Canadian news articles. Interestingly, this finding was opposite of Boyd et al. (2009) study with government as a theme only $11.6 \%$ in articles, as well as health having little news coverage $(5.8 \%)$. This difference in findings may be due to the time of sampling. Boyd et al. (2009) articles were sampled in the first 10 days of the initial BSE outbreak. This would have had little time for government policy change or direct actions toward the BSE outbreak, compared to the present study that sampled articles over two months of the initial COVID-19 case. This applies the same for health. Due to long periods of selfisolation or exposure to COVID-19 has significant health risks (i.e. mental or physiological) that may have not been as prevalent during the first period of an outbreak. Additionally, the current finding counters the finding of Lemyre et al. (2007) with the public perception of the news not being adequate in providing enough information about health-risks of BSE.

COVID-19 is framed as a health concern and a political concern rather than an economic concern. Thus, articles exemplified the importance of protecting one's health by practicing the rules the government endorsed, such as self-isolating, good hygiene, and social distancing (World Health Organization et al., 2020). This has a significant impact on how the public views COVID-19 under the social representation theory. The categorical themes the news media chooses to publish exerts an influence on how COVID-19 is perceived. Therefore, the current content analysis on thematic categories in Canadian news will provide insight on how risk 
communicators and health officials can effectively communicate risk to the public.

There are multiple limitations to this study that are to be addressed. First, the sample size of 50 articles may have not represented the population as effectively as a larger sample size would. Secondly, the articles were sampled from only one source, Facebook. Different articles may have been published on different sites (i.e. Twitter, news main website). It would be beneficial to sample articles from various websites. Lastly, I did not employ an inter-coder reliability test. This serves as a severe limitation due to the limited reliability and validity of the data collection.

Future studies can examine the public perception of COVID-19 correlating the perceptions of the thematic categories of news articles. Other potential future studies could examine articles published in local or provincial news channels rather than popular national news channels or combine local and national news channels to identify any differences or similarities between the news channels article publications.

\section{References}

Boyd, A. D., Jardine, C. G., Driedger, M. (2009). Canadian Media Representations of Mad Cow Disease. Journal of Toxicology and Environmental Health, 71, 1096-1105. doi: 10.1080/15287390903084629

Coleman, R., \& McCombs, M. (2007). The young and agenda-less? Exploringage-related differences in agenda setting on the youngest generation,baby boomers, and the civic generation. Journalism of Mass Communication, 84, 495508. 10.1177/107769900708400306

Coronavirus disease (COVID-19) advice for the public (2020). World Health Organization. Retrieved April 1, 2020 from https://www.who.int/emergencies/diseases/novelcoronavirus-2019/advice-for-public

Duncan, B. (2009). How the media reported the first days of the pandemic (H1N1) 2009: results of EU-wide media analysis EuroSurveill, 4(30), https://doi.org/10.2807/ese.14.30.19286-en

Epidemiological summary of COVID-19 cases (n.d.) Government of Canada. Retrieved April 1, 2020 from https://www.canada.ca/en/publichealth/services/diseases/2019-novel-coronavirusinfection/health-professionals/epidemiological-summarycovid-19-cases.html

Lai, C., Wang, C., Wang, Y., Hsueh, S., Ko, W., Hsueh, P. (2020). Global epidemiology of coronavirus disease 2019 (COVID-19): disease incidence, daily cumulative index, mortality, and their association with country healthcare resources and economic status. International Journal of Antimicrobial Agents, 16(26), 1-8.

https://doi.org/10.1016/j.ijantimicag.2020.105946

Höijer, B. (2011). Social representations theory: a new theory for media research. Nordicom, 32, 3-16. https://core.ac.uk/download/pdf/43557448.pdf

Lemyre, L., S. Gibson, M. P. L. Markon, J. E. C. Lee, I. Brazeau, A. Carroll, P. Boutette, \& Krewski, D. (2009). Survey of public perceptions of prion disease risks in Canada: what does the public care about?. Journal of Toxicology and Environmental Health, Part A, 72(17-18), 1113-1121.

Schwitzer G.(2004) Ten troublesome trends in TV health news. British Medical Journal, 329, 1352. https://doi.org/10.1136/bmj.329.7478.1352

Scheufele, D. A., \& Tewksbury, D. (2007). Framing, agenda setting, and priming: The evolution of three media effects models. Journal of Communication, 57, 9-20. https://doi.org/10.1111/j.0021-9916.2007.00326.x

Top 60 Canadian News Websites to Follow in 2020 (2020). Feedspot. Retrieved March 30, 2020 from https://blog.feedspot.com/canadian_news_websites

World Health Organization. (n.d.). Chapter 2: Threat to public health security. Retrieved March 30, 2020 from https://www.who.int/whr/2007/07_chap2_en.pdf?ua=1

Wray, R. L., Becker, S. M., Henderson, N., Glik, D., Jupka, K., Middleton, S., Henderson, C., Drury, A., \& Mitchell, E. W. (2008). Communicating with the public about emerging health threats: lessons from the pre-event message development project. American Public Health Association, 98(12), 2214-2222. https://ajph.aphapublications.org/doi/full/10.2105/AJPH.2 006.107102

Zhonghua, L. (2020). The epidomioloigcal characteristics of an outbreak of 2019 novel coronavirus disease (COVID-19) in China. Pubmed, 41(2), 124-151. doi: 10.3760/cma.j.issn.0254-6450.2020.02.003 